
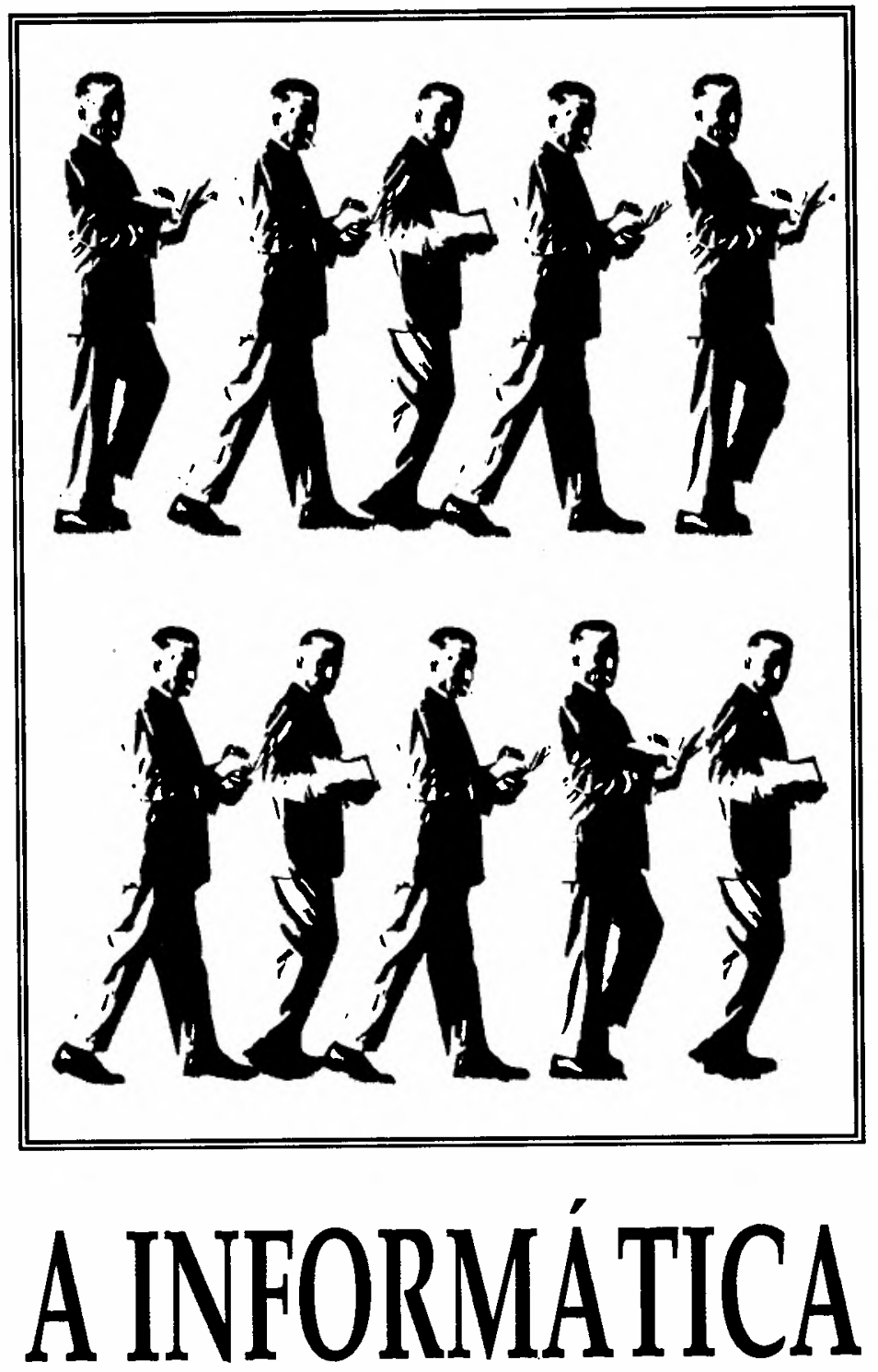

\title{
NA ORGANIZAÇÃO E NO TRABALHO
}

\section{- suzana bRAga RodRigues}

Coordenadora do CMA da Faculdade de Ciências Econômicas da Universidade Federa! de Minas Gerais.

\footnotetext{
tecnologia de informação ou informática, como empregamos no Brasil, são termos comumente atribuídos às atividades que envolvem processamento de informação e comunicação integrada através de equipamento eletrônico. Nesse sentido, aplicam-se igual-
}

mente à automação do processo de produção na manufatura que envolve a combinação da informação com a tecnologia mecânica, como no caso dos processos de monitoração e ajustamento da produção através de CNCs (máquinas de controle numérico) ou robôs.

As qualidades desse tipo de tecnologia, como tamanho, baixo custo, confiabilidade, flexibilidade, precisão, dentre outras, têm facilitado o seu emprego no setor industrial e ampliado as possibilidades de aplicação no setor de serviços.

O emprego de tecnologias avançadas no processo de produção, como CNCs, CAD 
(projeto assistido por computador), CAM (manufatura assistida por computador) e robôs, tem sido o foco de atenção principal dos que se preocupam com o impacto de novas tecnologias nas organizações. No entanto, é preciso lembrar que o setor de serviços é o maior comprador da informática. Por exemplo, em 1982, nos Estados Unidos, o setor de serviços adquiriu mais de $80 \%$ dos 25 bilhões de dólares gastos em computadores e equipamentos de escritório. No Brasil, a rapidez das aplicações da informática no setor de serviços vai depender, entre outros fatores, do sucesso da lei de reserva de mercado de 1982, e, portanto, da capacidade da indústria de supermini, mini e microcomputadores de produzir equipamentos de baixo custo e boa qualidade.

Mas já há alguns setores no país utilizandose, largamente, da informática, como o bancário, que tem acompanhado de perto a evolução tecnológica do setor financeiro nos países desenvolvidos. O Brasil já possui aproximadamente 5.000 agências interligadas através do sistema on line. Os dois maiores bancos comerciais brasileiros possuem ao todo 323 ATMs (Automated Teller Machines) que desempenham uma série de operações input de um cartão magnético como a produção do saldo, realizações de depósitos e pagamentos, estendendo o horário de funcionamento do banco com economia de pessoal. Os bancos mais modernos já possuem agências automatizadas que dispõem de terminais e de caixas automáticas que, através da digitação do código do cliente, realizam operações de depósito e saldo. Verdadeiramente revolucionários são os E.F.T. (terminais de transferência eletrônica de fundos) localizados em pontos comerciais estratégicos, como postos de gasolina e shoppings, que, através de um cartão magnético, fazem operações de débito direto na conta do cliente.

As aplicações da informática prometem transformações drásticas também no comércio através dos EPOS (terminais eletrônicos de pontos de venda) ou PDVs conforme os chamamos no Brasil. Alguns supermercados e lojas de departamentos já começaram a utilizar esse sistema que consiste de terminais ligados a um computador central que transmitem informações sobre as vendas diretamente ao estoque e à seção de compras. Atualmente, os EPOS usados no Brasil baseiam-se no sistema digital, mas brevemente o comércio brasileiro estará utilizando o registro magnético que se tornará viável com o código de barras desenvolvido recentemente a nível nacional.

As aplicações da informática no setor de serviços atingem até a medicina, com os computadores para autodiagnóstico e os sistemas de mo- nitoração de pacientes, com equipamentos que, além de mensuração contínua de dados vitais, podem até administrar medicamentos, automaticamente. Embora a aplicação da informática como instrumento auxiliar médico seja ainda incipiente no Brasil, já há alguns hospitais que vêm empregando os sistemas de informação de pacientes que integram informações relevantes sobre o cliente, como por exemplo: período de estada, diagnóstico, tratamento e custos.

Seja na indústria ou nos serviços, a informática vem sendo empregada dentro dos seguintes objetivos: melhoria da qualidade do produto ou serviços, controle de custos, necessidade de acompanhar a competição, maior quantidade e qualidade de informação e produtividade da força de trabalho. Mas os efeitos da informatização não se limitam às estratégias traçadas, indo além dos objetivos pretendidos pela empresa. As tecnologias da informação têm um impacto mais amplo na organização, podendo atingir áreas e encorajar procedimentos não previstos. A informática requer uma série de outras decisões que afetam a estrutura e processos organizacionais, e implica numa nova relação do empregado com o seu trabalho.

\section{EFEITOS SOBRE A ESTRUTURA E PROCESSOS ORGANIZACIONAIS}

Um dos aspectos mais discutidos da informática refere-se ao seu potencial de tornar redundantes certas ocupações. A redundância ocorre quando a necessidade do empregador de certo tipo de trabalho diminui ou cessa. A tecnologia da informação provoca um descompasso entre as habilidades disponíveis e as exigidas, mudando as relações de dependência da organização para com a mão-de-obra. Tivemos oportunidade de observar essa situação em um estudo que estamos desenvolvendo sobre o setor de serviços. A introdução das novas tecnologias de escritório afeta áreas de trabalho intensivo como datilógrafas, estenógrafas e arquivistas, ao mesmo tempo que cria funções gerenciais. No superatacado que estudamos, os postos de faturistas e kardecistas desapareceram, enquanto que postos a nível de gerência foram criados. A adoção de PDVs ligados a um computador central permite uma integração melhor do controle administrativo: os dados de venda são captados no caixa através dos terminais e são transmitidos diretamente ao controle de estoques que, por sua vez, transmite a informação à seção de compras. Esse tipo de tecnologia tornou desnecessárias não somente as funções relacionadas ao controle de estoque, mas algumas de supervisão ligadas à função de compras. Nos serviços, 
a unificação do controle administrativo que a informática permite pode levar a uma compressão do nível médio para baixo na hierarquia, com a eliminação de alguns postos de supervisão e outros relativos à compilação e registro manual de dados. Nesse mesmo superatacado, foram criados três postos a nível de gerência, enquanto foram eliminados três postos a nível de supervisão e dez ligados à função de controle de estoque.

Também na manufatura tem-se observado uma mudança no perfil de mão-de-obra. Algumas indústrias que passaram de um processo de produção eletromecânico para eletrônico, como a de relógios e telecomunicações, sofreram um processo de mudança estrutural. As empresas modernas têm um número maior de engenheiros e trabalhadores não qualificados.

Em geral, nas empresas que empregam as tecnologias novas no processo de fabricação, a proporção de white collars em relação aos blue collars inverteu-se; há menos trabalhadores manuais e mais técnicos, engenheiros, pessoas em pesquisa e desenvolvimento, em computação e serviços administrativos. Na manufatura, as estruturas administrativas tornaram-se redundantes em áreas de supervisão, monitoração e controle. Dada a redução da necessidade de inspeção, a função controle de qualidade acaba sendo reduzida e simplificada. Por outro lado, é criado espaço para outras funções ligadas ao planejamento, administração e manipulação de informação do equipamento.

Ao contrário do que se supõe, essas mudanças não representam pura e simplesmente alterações no perfil de mão-de-obra. Elas significam transformações muito maiores nas organizações, pois essas novas tecnologias criam novas especializações e hierarquias. Na área de sistemas, a própria divisão interna do trabalho é heterogênea, ou seja, há ocupações que exigem maior qualificação como as de criação, análise $e$ interpretação de informações e as que exigem menos habilidades - atividades destinadas a manipulações de informações. É justamente neste tipo de atividade que se encontra o emprego de mão-de-obra feminina, ou seja, de datilógrafas, secretárias, digitadoras, caixas. Já nos escalōes mais altos, estão as ocupações masculinas, profissionais, gerentes, programadores e analistas. A informática é, certamente, um instrumento destinado a assistir o trabalho desse último grupo e, para tanto, exige-se do primeiro rapidez e produtividade no processamento de informações. $\mathrm{Na}$ Suécia, um dos países mais avançados do mundo, $90 \%$ dos que trabalham na administração de processamento de dados e $80 \%$ dos que trabalham no planejamento são homens, e $97 \%$ dos que trabalham com digitação são mulheres.

Não temos dados globais sobre a divisão do trabalho no Brasil, mas tivemos oportunidade de observar situação semelhante no atacado que estudamos: enquanto os homens exerciam quase todas as funções de gerência e supervisão, as mulheres desempenhavam tarefas nos terminais de pontos de venda, de digitação e administrativas.

Outra tendência decorrente do impacto da informática é a burocratização da organização. $\mathrm{Na}$ empresa que estudamos, observamos o crescimento da área administrativa destinada à preparação de dados. Simultaneamente ao desenvolvimento dos sistemas, a empresa foi se tornando mais burocratizada. Antes do computador, a empresa não tinha informações precisas sobre o tamanho e características da força de trabalho e nem mesmo sobre seu desempenho econômicofinanceiro. Aos poucos, a firma passou a se conhecer melhor através do computador: o seu estoque, o faturamento, vendas, a clientela, contas a receber, os fornecedores, contas a pagar e competidores. $\mathrm{O}$ departamento de contabilidade tornou-se mais organizado e também o departamento de pessoal que, a partir daí, começou a adotar um sistema mais sistematizado de seleção. Os padrões de entrada e saída de mãode-obra modificaram-se; a empresa passou a dar maior importância à experiência de trabalho e a admitir um maior número de pessoas com educação superior, reduzindo, ao mesmo tempo, o número de empregados sem experiência $e$ analfabetos.

Esse mesmo processo pode ser encontrado em outras organizações. Porém, a extensão das mudanças vai depender do grau de burocratização anterior da organização. Parece claro que a informática e a burocracia não são independentes, ou seja, a informática é um veículo de padronização e normatização organizacional. Através de um estudo, que realizamos em um hospital, que introduziu um super minicomputador para propósitos administrativos, tivemos a chance de observar o desenvolvimento de uma série de controles pela organização. Com a introdução do computador, foram estabelecidos diversos controles administrativos, anteriormente inexistentes, como a definição do número de primeiras consultas e retornos por dia e por clínica, horário para marcar consultas, definição prévia do período de férias dos funcionários, etc.

Surpreendentemente, em algumas organizações a burocratização deixa de ser racional e passa a ser disfuncional. Como o computador facilita o estabelecimento de procedimentos ou 
regras escritas, a organização passa a criar uma série de relatórios e formulários que não são sequer analisados ou interpretados. Verificamos que, em algumas empresas de prestação de serviços, a informática facilita a criação de formulários bem detalhados sobre o uso de veículos ou equipamentos cujos dados são compilados através do computador, mas não são nunca examinados.

As disfunções manifestam-se também através da redundância do sistema, ou seja, há organizações que conferem manualmente os relatórios emitidos pelo computador. No atacado onde realizamos nosso estudo, verificamos que alguns postos foram criados com o objetivo exclusivo de conferir o trabalho já realizado automaticamente pelo computador, como os cargos ligados à conferência de estoques.

Esse tipo de disfunção pode ser resultado de um processo de aprendizagem, no qual não se confia ainda o suficiente na nova tecnologia. Contudo, é necessário entender que esse tipo de conduta impõe um custo financeiro e humano para a organização. Normalmente, a informática é empregada nas empresas como um instrumento de otimização de recursos. No entanto, é comum encontrarmos a situação de redundância na organização do trabalho apesar da informática. No atacado que estudamos, a implantação de pontos eletrônicos de venda, ligados a um computador central, levou a um aumento de 15 pessoas na área do caixa em vez de redução. É que, nesse caso, a organização do trabalho não acompanhou a mudança tecnológica, permanecendo a redundância característica do sistema anterior. $O$ trabalho foi organizado de modo a evitar erros no registro da saída de mercadorias, mas à custa de uma maior segmentação das tarefas, implicando também em maiores gastos financeiros. Havia quatro postos de trabalho, a meu ver redundantes, destinados à conferência e à conferência da conferência. $O$ mais interessante era que a organização não mantinha registro do número de erros.

Assim, a informática, em vez de levar a um processo de racionalização organizacional, acaba criando disfunções burocráticas. Em organizações públicas, a situação é mais grave, uma vez que as tecnologias de informação substituem algumas tarefas humanas, economizando mão-de-obra. Os relatórios, formulários e outros instrumentos de padronização transformam-se, então, numa estratégia de criação de trabalho e mesmo de sobrevivência, uma vez que a organização pública dentro da estrutura organizacional atual tem que conviver com o excesso de mão-de-obra e tecnologias que economizam recursos humanos.
Cabe lembrar que o problema da burocratização está diretamente ligado à questão dos processos de controle organizacionais e à centralização de decisões. O potencial da informática faz com que o controle gerencial possa ser exercido sem a necessidade de relações diretas com os subordinados. Tecnologias como máquinas de controle numérico, processadores de palavras, terminais eletrônicos de pontos de venda permitem o controle mais preciso da produtividade, registrando horas paradas, número de erros, rapidez do trabalho. Os terminais inteligentes, além disso, requerem mais disciplina fazendo com que o trabalhador siga o ritmo da própria máquina.

A informática muda, portanto, o sentido da supervisão e aumenta o potencial para o controle administrativo, uma vez que permite a obtenção de medidas mais precisas, melhora a capacidade de comunicação à distância e possibilita a aplicação de rotinas sintetizantes. Uma outra aplicação é que a direção não tem mais que se basear na gerência média para obtenção de informações. Na medida em que as novas tecnologias melhoram os sistemas de informação, elas fazem com que certas informações viajem com maior rapidez do nível operacional ao gerencial, favorecendo a centralização de decisões.

As tecnologias da informação promovem a unificação de sistemas de controles fragmentados tanto na indústria quanto nos serviços. A integração é facilitada na medida em que a mesma informação se torna acessível a diferentes departamentos através do acesso a um arquivo comum. A IBM, por exemplo, criou uma rede cooperativa que envolve a interligação entre 60.000 terminais e proporciona acesso imediato a informações básicas sobre a companhia.

Os sistemas de admissão de pacientes que estão sendo implantados em alguns hospitais permitem a integração das informações sobre o paciente: diagnóstico, exames, tratamento, tempo de estada. Ao mesmo tempo, é possível conciliar os dados da internação, farmácia e compras. No comércio, a combinação de terminais de venda com o computador central facilita a unificação do controle dentro da loja, conciliando informações sobre venda, estoque nas prateleiras, controle de caixa, alocação de pessoal e compras.

A conseqüência natural da unificação do controle é, portanto, a centralização, pois não haveria necessidade de a administração média funcionar como intermediária do processo de integração das atividades organizacionais. Alénı disso, o controle administrativo pode ser melhorado através de mudanças no software.

As tecnologias da informação, portanto, têm 
capacidade para modificar a estrutura organizacional e os processos administrativos, como padrões de controle e supervisão. Seus efeitos não se restringem, porém, ao nível da organização, pois a informática muda também a relação do indivíduo com o seu trabalho.

\section{EFETTOS SOBRE O TRABALHO E O TRABALHADOR}

As experiências de implantação de um sistema computadorizado de informações sugere que o impacto da tecnologia se dá, num primeiro instante, a nível das relações homemmáquina.

Quando o trabalho que era manual passa a ser mediado pelo computador, ocorre uma mudança na natureza da tarefa que altera fundamentalmente a relação do indivíduo com a mesma. O trabalho mediado por computador envolve a manipulação eletrônica de dados e caracteriza-se por ser uma atividade abstrata ao invés de uma atividade sensorial e concreta. Isso significa que o individuo passa a lidar com a tarefa por intermédio do sistema de informação mais do que através do contato direto físico com o trabalho. Na tarefa manual, um arquivista manipula as fichas e entra em contato físico com as mesmas. Com o computador, a visualização concreta do fichário se perde, pois as fichas podem estar em qualquer ponto imaginário da "caixa-preta".

Tivemos oportunidade de observar isso tanto no trabalho em bancos quanto em hospitais. Anteriormente ao sistema on line, as informações a respeito do saldo do cliente no banco eram buscadas nas listagens e nas fichas individualizadas confeccionadas à noite nos centros de processamento de dados. Com os caixas automáticos, as informações a respeito da situação financeira dos clientes são arquivadas em qualquer ponto da "caixa-preta". Além disso, a tarefa de caixa requer mais uma abstração, ou seja, as informações a respeito das transações devem ser armazenadas através dos códigos que as identificam. Antes, o caixa tinha que registrar apenas as operações de saque e depósito. No novo sistema, as operações devem ser registradas especificando-se através de códigos a natureza da operação, a praça, a agência do cliente, etc.

Situação semelhante ocorre nos sistemas de admissão para consultas em hospitais. O hospital que estudamos fornece um bom exemplo à introdução da informática na organização. Anteriormente, as consultas eram marcadas manualmente, e, para tanto, era necessário consultar a agenda médica ou cadastro do cliente, registrando-se em seu cartão o dia, o horário da consulta e o nome do médico. Com a introdução dos terminais, as fichas de consulta, as agendas médicas e os prontuários de clientes passaram a ser feitos pelo computador. Para marcar a consulta, passou a ser necessário verificar a agenda médica através dos terminais, o que exigia a manipulação correta de símbolos. As funcionárias afirmaram que esse novo esquema gerou bastante insegurança e uma sensação de perda de controle da situação, pois todas as informações estavam armazenadas na memória da máquina. A tarefa das atendentes tornou-se mais abstrata uma vez que tinham que localizar os horários vagos por clínica e por médico e ainda na data desejada pelo cliente. A nova tarefa não implicava em manipulação concreta do arquivo que, ao contrário, passou a ser representado simbolicamente através das informações no vídeo.

Embora as tecnologias da informação impliquem numa mudança nas relações com a tarefa, podendo exigir em certos casos mais abstração ou novas habilidades, é necessário ter um certo cuidado para não cair em generalizações ou simplificações incorretas. $O$ estudo que estamos desenvolvendo nos leva a crer que a maneira como a informática afeta o trabalhador depende de decisóes da administração a respeito das características e capacidade do equipamento a ser selecionado e de decisões acerca da organização do trabalho.

Os equipamentos que estão sendo utilizados nos países mais avançados, à base da caneta magnética, podem, certamente, tornar redundante $e$, conseqüentemente, desempregada a maioria do pessoal que dá apoio ao caixa estilo convencional. Isso vale também para os terminais de pontos de venda baseados no sistema digital, principalmente naqueles estabelecimentos onde há necessidade de discriminação da nota fiscal. As estratégias de automação bancária através das ATMs têm potencial para produzir mais desemprego do que as tecnologias baseadas em caixas automáticos que necessitam da intervenção humana.

Mas, em qualquer caso, o fator principal é a organização do trabalho, pois é através dela que se determinam a divisão e o conteúdo das tarefas e se estabelecem as condições nas quais os recursos humanos são alocados. A maneira como o trabalho é organizado tem influência no nível de stress e na satisfação do empregado.

Conforme sugerimos anteriormente, as tecnologias da informação podem provocar stress se a mudança na natureza da tarefa for drástica, como no caso da passagem de um sistema manual para o mediado por computador. Aí, nesse caso, são importantes a forma como o trabalho é organizado bem como as características da tarefa 
anterior. Existem formas de organização do trabalho que agravam a situação de tensão provocada pela introdução de terminais. Isso acontece quando o trabalho é intermediado por duas tecnologias diferentes.

A inovação na marcação de consultas no hospital que estudamos pode servir de exemplo. No novo sistema, as consultas eram marcadas através dos terminais e por telefone. A maioria das funcionárias da seção declarou que esse sistema provoca mais stress, pois o ritmo de trabalho era determinado pela freqüência das chamadas e pelo ritmo em que a máquina processava as informações. $O$ contato com o cliente era resumido, indireto e, às vezes, tenso. Como o contato telefônico era difícil, pois as linhas estavam sempre ocupadas, e usualmente ocorria alguma demora no processamento das informações pelo computador, havia muitas reclamações dos usuários, que atribuíam as falhas às telefonistas. Além disso, a tarefa no telefone e nos terminais era duplamente repetitiva e monótona para a operadora. Os efeitos das tecnologias de informação sobre o trabalhador dependem não só da organização do trabalho, mas são também relativos à função que este exercia previamente. Se o empregado já desempenhava tarefas de caráter rotineiro e repetitivo e já intermediado por alguma tecnologia mecânica ou mesmo eletromecânica, é pouco provável que a introdução de sistemas de informação baseados na microeletrônica possa trazer mudanças substanciais na natureza da tarefa.

É preciso lembrar, no entanto, que a informática afetá não só aquelas funções mediadas por computador, mas também outras interligadas ao fluxo de informações geradas pelo sistema. Gerentes, supervisores e pessoal administrativo vêem a informática de diferentes maneiras. Tanto no comércio quanto no setor bancário, o emprego da informática torna o desempenho do gerente muito mais visível. No caso dos bancos, os sistemas de informações permitem o acompanhamento mais preciso e imediato do cumprimento das metas dos bancos. Através da informática, a matriz ou a regional podem acompanhar diariamente o cumprimento das metas em relação aos diversos produtos dos bancos. Exige-se, por outro lado, mais dos gerentes das agểncias modernas, com base no argumento de que a gerência possui a sua disposição tecnologias avançadas que facilitam a venda dos serviços bancários. Ademais, como a automação economiza tempo do gerente na busca de informações sobre a situação do cliente, sobra mais tempo para o contato com clientes especiais. Requerem-se, por isso, mais assertividade e desempenho na venda dos ser- viços.

Portanto, a informática traz consigo algumas mudanças no estilo de gerência que são encaradas de maneira positiva. Mas, os gerentes reconhecem que a possibilidade de controle e acompanhamento mais imediato gera mais stress. Segundo o depoimento de alguns gerentes de banco, a informática facilita o contato com os subordinados e com os clientes e agiliza as tarefas, deixando mais tempo para a venda de serviços. Em geral, os gerentes de agências automatizadas sentem-se privilegiados por trabalharem na mesma. Mas alguns acham que a automação através das ATMs tornou o trabalho da gerência mais difícil, pois tendem a afastar o cliente do banco. Segundo eles, os sistemas de automação dos serviços ao cliente tendem a torná-lo independente da gerência, e a transformar as relações entre cliente e banco, tornando-as mais impessoais. Contudo, a automação bancária requer mais esforço do gerente: o cliente do banco automatizado é mais exigente; normalmente esperase que a venda de serviços compense os custos de automação e, além disso, a automação torna a competição interbancária mais difícil.

Fenômeno similar ocorre no comércio. Também aqui, a gerência acha que o desempenho é mais cobrado através dos relatórios. Os erros são mais visíveis e detectados facilmente. Há agora a necessidade de saber que relatórios devem ser produzidos para qual fim e como interpretá-los. As firmas ressaltam que fizeram um investimento de alto custo e cabe à gerência a responsabilidade de fazê-lo funcionar. Apesar do stress que o novo sistema gera, a aplicação da informática é vista como positiva, pois tem um impacto direto nas relações com os clientes e, conseqüentemente, no desempenho da firma. Os terminais eletrônicos de venda agilizam o registro de vendas, reduzindo o tamanho das filas e deixando a clientela mais satisfeita com os serviços. No estabelecimento comercial que estudamos, o número de clientes aumentou em $174 \%$ e o faturamento em $249 \%$, no ano seguinte à implantação dos terminais de PDV.

Tanto no comércio quanto no setor bancário, as tarefas do caixa são alteradas apenas marginalmente pela introdução da informática. Em ambos os casos, as tarefas já eram repetitivas e mediadas por uma tecnologia mecânica ou eletromecânica. $\mathrm{O}$ bancário reconhece que com os caixas eletrônicos o seu trabalho se tornou mais abstrato e exige maior atenção. Há alguns exemplos no comércio atacadista em que as exigências do trabalho se tornaram menores. No sistema antigo, quando as notas fiscais eram datilografadas, exigiam-se datilógrafas para o exercício da função. Com os terminais eletrônicos, a nota fis- 
cal passou a ser feita pelo computador, através dos caixas, nos pontos de venda, sendo necessário apenas registrar-se o código dos produtos.

As operadoras dos terminais que registram as notas fiscais vêem a nova tecnologia como um fator positivo, pois acham que ela traz uma série de vantagens, como a mobilidade vertical e melhores oportunidades no mercado de trabalho. Nos PDVs, existe mais autonomia, segundo elas, pois há menos supervisão direta. A rapidez de atendimento através dos terminais reduz os atritos com os clientes e com os superiores. O stress é menor e há mais satisfação no trabalho.

Nos bancos, algumas tecnologias como caixas automáticos exigem a participação mínima do bancário. Em outros casos, como por exemplo, os terminais de cliente e ATMs excluem completamente a participação do caixa, pois são baseados no auto-serviço. Apesar disso, os caixas não vêem as máquinas como rivais que vêm incorporando as suas funções através do software. Ao contrário, apreciam trabalhar com tecnologias avançadas e acham que a informática assumiu parte da responsabilidade do seu trabalho. Não há mais preocupações com erros a respeito de cheques sem fundos, pois a máquina rejeita automaticamente a operação de saque em casos de ausência de fundos. As relações com os clientes melhoraram, apesar de o cliente exigir mais desempenho do funcionário quando a agência é automatizada, pois argumenta que o funcionário dispõe de mais recursos tecnológicos, não podendo errar nem delongar no seu desempenho. Os caixas se ressentem da falta do relacionamento mais pessoal com a gerência, que ocorre ainda nas agências tradicionais. Conforme sugerimos anteriormente, o gerente dispõe de menos tempo para questões administrativas e está sendo incentivado a ser mais agressivo na venda dos produtos bancários.

A informática agiliza a prestação de serviços de maneira geral. Diferentemente do que preconizam seus entusiastas, as tecnologias da informação não permitem ao empregado dedicar-se a tarefas mais interessantes, exceto em alguns casos. A aplicação efetiva dos sistemas tem como resultado a melhoria da qualidade dos serviços e, conseqüentemente, o aumento da clientela. Isso implica, evidentemente, em maior volume de trabalho. De um modo geral, o aumento do ritmo e do volume tem consequiências para o fluxo de trabalho e atinge a organização como um todo, independentemente da categoria ocupacional ou nível hierárquico. $\mathrm{O}$ aumento do ritmo e volume do trabalho, por outro lado, não afeta de maneira significativa o empregado a ponto de exacerbar as condições de tensão no trabalho. Outros fatores são mais importantes nesse caso. Para as funções cujo desempenho depende de interação direta com a clientela, as interrelações com o cliente são críticas. Se o contato com a clientela é ruim porque a qualidade dos serviços deixa a desejar, geralmente há tensão no trabalho. Se a aplicação de sistemas tem por objetivo melhorar a qualidade dos serviços prestados e é feita de maneira eficiente, um dos resultados é a redução das tensões no trabalho. Pudemos observar essa situação no atacado que estudamos, e o contrário no hospital, onde a implementação inadequada dos sistemas piorou a qualidade dos serviços prestados, criando atritos com os clientes e aumentando as tensões dos atendentes.

Em geral, os empregados reagem de forma diferenciada às tecnologias de informação, dependendo da categoria ocupacional ou posição na hierarquia. Podemos dizer que os pontos favoráveis pesam mais a nível de gerência do que para as operadoras dos terminais. Para os trabalhadores não qualificados (que executam tarefas de apoio às operadoras de terminal), os pontos a favor pesam tanto quanto os contra, isto é, o impacto do computador não é tão representativo (Figura na página seguinte).

No caso da empresa comercial que estudamos, a informática é vista como positiva por diferentes categorias ocupacionais. Predomina a idéia de que as tecnologias novas equivalem a progresso, por isso são boas, não havendo razão para questioná-las. Simbolizam prestígio e status, tanto para os gerentes quanto para os supervisores e trabalhadores em geral. Num país em que o emprego da informática é incipiente, é natural que tenham reconhecimento aqueles que conseguem desvendar os seus mistérios. Atribuem-se, portanto, poderes à tecnologia que ela própria não tem, como o de possibilitar a ascensão na empresa ou de melhorar as oportunidades no mercado de trabalho.

Embora a informática seja aplicada em organizações dentro de certos objetivos, existe uma grande diferença entre o potencial das tecnologias de informação e suas realizações. A tentativa de se resolverem problemas através da estratégia de informatização traz certas conseqưências planejadas e não planejadas para a organização, o trabalho e o trabalhador, que devem ser avaliadas, mesmo antes de se tomarem as decisões sobre a compra dos equipamentos.

A ação administrativa, diante das novas tecnologias, deveria, portanto, começar com o reexame da estrutura organizacional, das rotinas, controle administrativo e dos sistemas de supervisão. A informática não tem condições de atingir os objetivos pretendidos se não for acompa- 
Figura: Efeitos percebidos da introdução de PDVs em um Superatacado

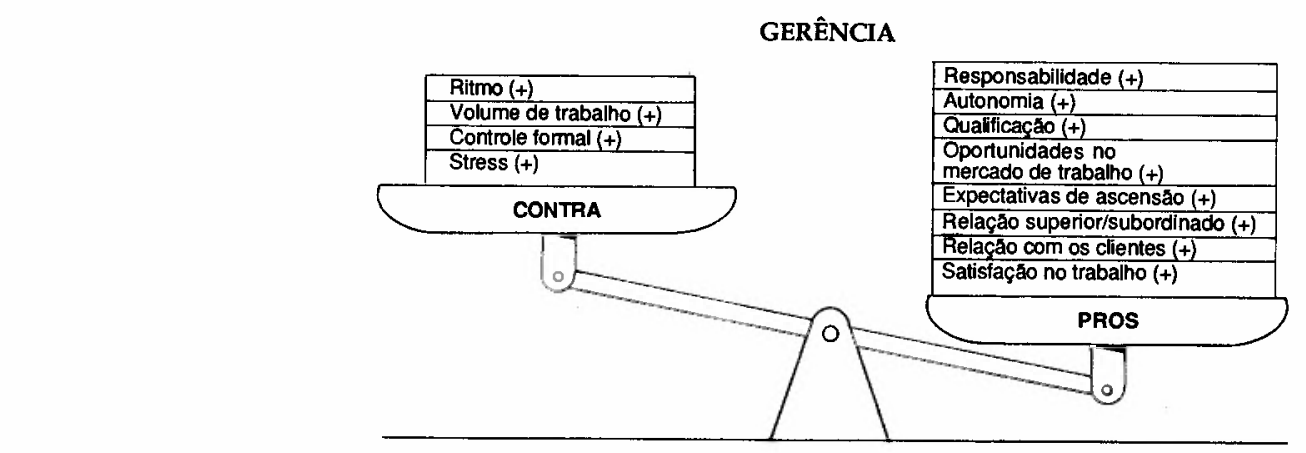

OPERADORES DE PDVS
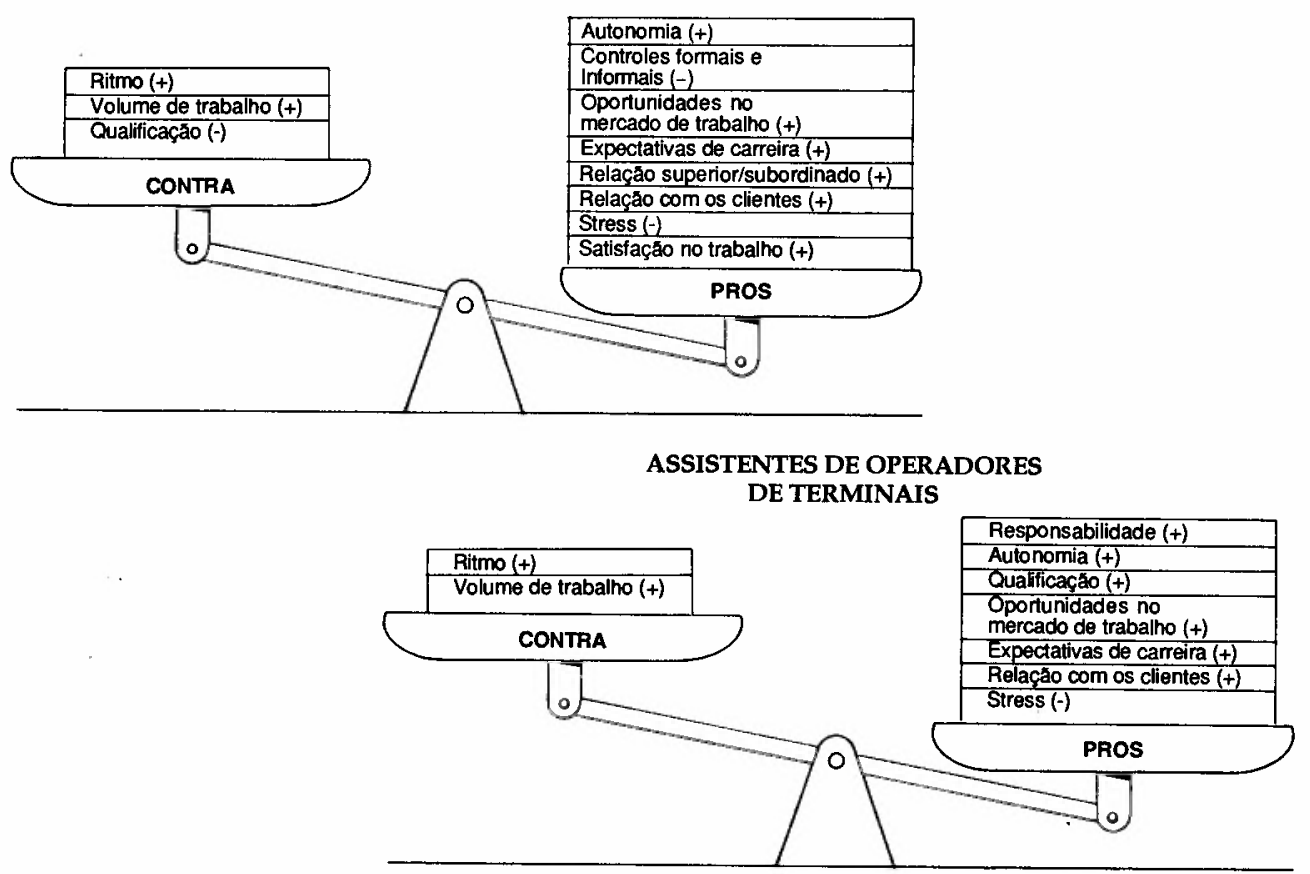

Em: RODRIGUES, S. B. - Microelectronics and Work Organization in the Services. Trabalho apresentado na Universität Mannheim, Alemanha, maio 1986.

nhada de um desenvolvimento na área burocrática, se não houver um reajustamento dos padrões de controle e supervisão.

Dissemos que os efeitos das tecnologias sobre o trabalho não são inexoráveis, isto é, dependem da escolha tecnológica e da maneira como o trabalho é organizado. Isso implica em novas possibilidades de atuação para o profissional de recursos humanos, pois as opções vão além da segmentação do trabalho e do desemprego. É possível chegar-se a arranjos do trabalho que venham a qualificá-lo em vez de degradá-lo.
Mas isso requer uma reavaliação da primazia que é dada a critérios econômicos e sociais na organização do trabalho.

A informática, portanto, impõe novos desafios à gestão de recursos humanos que terá de repensar algumas de suas funções básicas como a seleção e treinamento. Visualizamos um importante papel para o gerente de RH na preparação para a informatização da empresa, desde o diagnóstico, previsão das implicações, até o reajustamento na divisão do trabalho e mesmo reeducação. 